\title{
ACOMPANHAMENTO CLÍNICO-SOROLÓGICO DE PROFISSIONAIS DE SAÚDE EXPOSTOS A MATERIAIS BIOLÓGICOS DE PACIENTES PORTADORES DE VÍRUS DE IMUNODEFICIÊNCIA HUMANA (HIV)
}

\author{
Ledice Inácia de Araújo Pereira, Marta Antunes de Souza, Luiz Carlos \\ Silva Souza, Anita Bernardes da Silva, Ivete Vieira Gomes \& \\ Raimundo Nonato Leite Pinto ${ }^{\circ}$
}

\begin{abstract}
RESUMO
O Hospital de Doenças Tropicais vem fazendo acompanhamento de seus profissionais de saúde com exposição ocupacional a materiais biológicos de pacientes HIV positivos desde 1986. quando, ocorreram as primeiras internaçōes.

No período de julho de 1986 a outubro de 1992 ocorreram 579 internaçōes por AIDS. Foram notificadas 37 exposiçōes ocupacionais, destas 22 com materiais biológicos de pacientes HIV positivos. A mais freqüente foi do tipo perfuraçāo (12 vezes) causada por agulhas e "scalps" em 17 casos. As regiōes do corpo mais atingidas foram os dedos das māos. Técnicos e auxiliares de enfermagem constituíram o grupo com maior número de exposiçōes. Os procedimentos mais freqüentemente envolvidos foram: punção venosa, manuseio do cateter venoso e descarte de agulhas. Foi realizado teste imunoenzimático (ELISA) para detecção de anticorpos anti-HIV em todos os profissionais na época do acidente, com resultado negativo. Foi entâo proposto acompanhamento sorológico após 3 a 6 meses do acidente. No momento. há 13 profissionais com acompanhamento igual ou maior que 6 meses ( 3 só fizeram o $1^{\circ}$ exame e os demais ainda estāo em fase de observação). Não foi registrada soroconversão e nenhum dos profissionais desenvolveu sintomas clínicos de infecçāo aguda pelo HIV.
\end{abstract}

UNITERMOS: Infecçāo hospitalar, Exposição ocupacional

\section{INTRODUÇĀO}

O tratamento de pacientes portadores do vírus da Imunodeficiência Humana tem sido causa de medo e preconceito para muitos profissionais de saúde.

• DMT - IPTSP - UFG E HOSPITAL DE DOENÇAS TROPICAIS-SUS/GO

- Recebido para publicação em 15/01/94 
PEREIRA,L.I.A.;SOUZA,M.A.;SOUZA,L.C.S;SILVA,A.B.;GOMES,I.V.;PINTO,R.N.L. Acompanhamento clínico-sorológico de profissionais de saúde expostos a materiais biológicos de pacientes portadores do Virus da Imunodeficiência Humana (HIV). Rev.Pat.Trop.23(1):25-37, jan./jun.1994.

Conseqüentemente questionamentos técnicos e éticos a respeito da doença, do doente e do atendimento profissional estão presentes no cotidiano dos hospitais (1).

Os trabalhadores das instituições hospitalares estāo expostos a vários graus de riscos decorrentes de suas atividades. Estudos prospectivos sobre risco ocupacional de infecção por HIV em profissionais de saúde têm demonstrado risco de $0,22 \%$ a $0,56 \%$ em contatos percutâneos $(3,4,5)$.

As normas para prevenção de transmissão do HIV em hospitais são bem definidas $(6,7)$ assim como as recomendaçōes para acompanhamentos daqueles que tiveram exposição ocupacional ao vírus (8-9).

Em Goiás, o Hospital de Doenças Tropicais iniciou, em julho de 1986, o atendimento a pacientes protadores de HIV. Desde então, a Comissão de Controle de Infecção Hospitalar vem desenvolvendo programa de treinamento para profissionais de saúde e seguindo prospectivamente aqueles expostos a materiais biológicos de pacientes.

O objetivo do presente trabalho é relatar o acompanhamento clínico-sorológico de 22 profissionais de saúde expostos a material biológico de pacientes HIV positivos, no período de julho de 1986 a outubro de 1992.

\section{MATERIAL E MÉTODOS}

Após exposição a Comissão de Controle de Infecção hospitalar era notificada e o funcionário convocado para uma entrevista, ocasião em que preenchia uma ficha de notificação (ver em anexo) com os seguintes dados: identificação e antecedentes do profissional, local e hora do acidente, descrição da exposiçāo, diagnóstico do paciente e procedimento que estava sendo realizado. Fazia-se então exame clínico e orientação do funcionário, que assinava um termo de recusa ou consentimento para acompanhamento clínico e sorológico. Para o exame sorológico (anticorpos anti-HIV) foi utilizado o método imunoenzimático-ELISA, realizado, imediatamente, após o contato e após 3 a 6 meses.

O profissional obteve instruçōes para relatar todas as doenças contraídas nos primeiros 6 meses após exposição.

\section{RESULTADOS}

No período de junho de 1986 a outubro de 1992 ocorreram 579 internaçōes por AIDS no Hospital de Doenças Tropicais-SUS-GO e foram notificadas 37 exposiçōes ocupacionais sendo $22 \mathrm{com}$ materiais biológicos de pacientes HIV
PEREIRA,L.I.A.;SOUZA,M.A.;SOUZA,L.C.S;SILVA,A.B.;GOMES,I.V.;PINTO,R.N.L. Acompanhamento clínico-sorológico de profissionais de saúde expostos a materiais biológicos de pacientes portadores do Vírus da Imunodeficiência Humana (HIV). Rev.Pat.Trop.23(1):25-37, jan.jun.1994.

positivos (Tabela 01). Os técnicos e auxiliares de enfermagem foram os mais expostos $(45,5 \%)$ seguidos dos auxiliares de enfermagem $(18,2 \%)$ e servidores da área de limpeza $(13,8 \%)$ (Tabela 02$) .13$ casos $(59,1 \%)$ têm acompanhamento sorológico igual ou maior que 6 meses; 4 casos $(18,2 \%)$ igual ou maior que 3 meses; 2 casos $(9,1 \%)$ têm apenas o exame pós-exposição e 3 casos $(13,6 \%)$ não seguiram a recomendação (Tabela 03 ).

Tabela 1 - Total de internaçōes, número de internaçōes de pacientes com AIDS, total de exposiçōes profissionais e contato envolvendo material biológico de pacientes HIV positivos no Hospital de Doenças Tropicais no período de julho de 1986 a outubro de 1992.

\begin{tabular}{|c|c|c|c|c|c|c|}
\hline \multirow[b]{2}{*}{ Ano } & \multirow{2}{*}{$\begin{array}{l}\text { Total de } \\
\text { Internaçōes }\end{array}$} & \multicolumn{2}{|c|}{$\begin{array}{l}\text { Internaçōes } \\
\text { Pacientes c/AIDS }\end{array}$} & \multirow{2}{*}{$\begin{array}{l}\text { Total de } \\
\text { exposiçōes } \\
\text { profissionais }\end{array}$} & \multicolumn{2}{|c|}{$\begin{array}{l}\text { Exposiçóes relacionadas } \\
\text { a pacientes HIV positivos }\end{array}$} \\
\hline & & $n^{\circ}$ & $\%$ & & $\mathrm{n}^{\circ}$ & $\%$ \\
\hline 1986 & 2529 & 04 & 0,15 & 01 & 01 & 100,00 \\
\hline 1987 & 1748 & 29 & 1,65 & 01 & 01 & 100,00 \\
\hline 1988 & 1825 & 51 & 2,79 & 04 & 04 & 100,00 \\
\hline 1989 & 1802 & 59 & 3,27 & 02 & 02 & 100,00 \\
\hline 1990 & 2285 & 91 & 3,98 & 05 & 04 & 80,00 \\
\hline 1991 & 1150 & 164 & 14,26 & 08 & 05 & 62,50 \\
\hline $1992^{\circ}$ & 975 & 129 & 13,23 & 16 & 05 & 31,25 \\
\hline $\begin{array}{l}\text { TOTA } \\
\text { *Até }\end{array}$ & $\begin{array}{l}12314 \\
\text { lubro }\end{array}$ & 579 & 4,70 & 37 & 22 & 59.45 \\
\hline
\end{tabular}

As agulhas e "scalps" foram relacionados como os agentes que mais freqüentemente provocaram exposiçōes $(77,3 \%$ ) (Tabela 04). As perfuraçōes foram observadas em $59,1 \%$ dos casos (Tabela 05 ). Os dedos das mãos foram as regiōes do corpo mais expostas $(54,5 \%)$ (Tabela 06). A punção venosa, manuseio do cateter venoso e descarte de agulha estavam entre os procedimentos de maior risco (Tabela 07).

Nenhum profissional desenvolveu doença compatível com infecção aguda por HIV e nem apresentou soroconversāo. 
PEREIRA,L.I.A.SOUZA,M.A.SOUZA,L.C.S;SILVA,A.B.GOMES,IV.PINTO,R.N.L. Acompanhamento clínico-sorológico de profissionais de saúde expostos a materiais biológicos de pacientes portadores do Vírus da Imunodeficiência Humana (HIV). Rev.Pat.Trop.23(1):25-37, jan.jjun.1994.

Tabela 2 - Atividade profissional dos indivíduos expostos a sangue e secreçōes de pacientes HIV positivos no HDT no período de julho de 1986 a outubro de 1992.

Atividade profissional

$\mathrm{n}^{\circ}$

Téc. e Aux.Enfermagem

Serviços gerais

Téc. laboratório

Téc. necrópsia

Enfermeiros

Médicos

\begin{tabular}{lr}
14 & 63,7 \\
03 & 13,6 \\
02 & 9,2 \\
01 & 4,5 \\
01 & 4,5 \\
01 & 4,5 \\
\hline
\end{tabular}

TOTAL

22

100,0

Tabela 3 - Acompanhamento clínico-sorológico de profissionais de saúde expostos a material biológico de pacientes HIV positivos. Hospital de Doenças Tropicais. Julho de 1986 a outubro de 1992.

clínico-sorológico

\section{$\geq 6$ meses}

$\geq 6$ meses

A 3 menas exame pós-exposiça

Não seguiram recomendação

$13 \quad 59,1$

TOTAL

22

100,0

Tabela 4 - Agentes relacionados com exposiçāo profissional a sangue e secreçōes de pacientes HIV positivos no HDT no período de julho de 1986 a outubro de 1992.

\section{Agentes}

\section{AGULHAS E "SCALPS"}

LUVA FURADA

AMPOLA

PONTEIRA DE PIPETA

LIMPEZA DE FERIDA

\begin{tabular}{lr}
17 & 77,3 \\
02 & 9,2 \\
01 & 4,5 \\
01 & 4,5 \\
01 & 4,5 \\
\hline
\end{tabular}

TOTAL

22

100,0
PEREIRA.L.I.A.:SOUZA,M.A.SOUZA.L.C.S;SILVA,A.B.GOMES,IV.PINTO,RN. Acompanhamento clínico-sorológico de profissionais de saúde expostos a materiais biológicos de pacientes portadores do Vírus da Imunodeficiência Humana (HIV). Rev.Pat.Trop.23(1):25-37, jan.jun.1994.

Tabela 5 - Tipo de exposição profissional ao sangue e líquidos corpóreos de pacientes HIV positivos observados no HDT no período de julho de 1986 a outubro de 1992.

\begin{tabular}{llr}
\hline Tipo de exposição & $\mathrm{N}^{\circ}$ & $\%$ \\
\hline Perfuração & 13 & 59,1 \\
Respingo de sangue em mucosa & 04 & 18,3 \\
Sangue em pele lesada & 02 & 9,1 \\
Respingo em pele sã & 01 & 4,5 \\
Corte & 01 & 4,5 \\
Laceraçāo & 01 & 4,5 \\
\hline TOTAL & 22 & 100,0
\end{tabular}

Tabela 6 - Regiōes do corpo que tiveram contato com sangue ou secreçōes de pacientes HIV positivos observados no HDT no período de julho de 1986 a outubro de 1992.

\begin{tabular}{llr}
\hline Regiōes do corpo & $\mathrm{N}^{\circ}$ & $\%$ \\
\hline Dedos das mãos & 12 & 54,5 \\
Mão & 04 & 18,2 \\
Mucosa ocular & 04 & 18,2 \\
Antebraço & 01 & 4,5 \\
Face & 01 & 4,5 \\
\hline TOTAL & 22 & 100,0
\end{tabular}

\section{DISCUSSĀO}

O risco de se adquirir AIDS após exposiçāo profissional é conhecidamente baixo, mas real $(4,5,10,11,12)$. Depende de vários fatores como o número e tipo de contatos experimentados pelo profissional e número de pacientes infectados pelo HIV atendidos por ele (13). Nos estudos prospectivos, os casos de soroconversão estão relacionados com exposiçōes percutâneas, o mesmo não ocorrendo nas cutâneas ou mucosas $(3,4,5)$. 
PEREIRA,L.I.A.;SOUZA,M.A.;SOUZA,L.C.S;SILVA,A.B.;GOMES,I.V.;PINTO,R.N.L. Acompanhamento clínico-sorológico de profissionais de saúde expostos a materiais biológicos de pacientes portadores do Vírus da Imunodeficiência Humana (HIV). Rev.Pat.Trop.23(1):25-37, jan./jun.1994.

O uso de medidas protetoras para manuseio de agulhas, "scalps" e outros instrumentos de corte e ponta é fundamental para a profilaxia de transmissão de HIV e outros patógenos do sangue. Dessa forma, deve-se priorizar programas institucionais de prevenção e controle e considerar o uso de Zidovudine (AZT) nas exposiçōes de maior risco. Nos estudos prospectivos relativos à profilaxia com AZT após exposição profissional não ocorreram soroconversões, mas sua eficácia só poderá ser comprovada com estudo prospectivo envolvendo um grande número de trabalhadores expostos: Por outro lado, já existem casos de soroconversāo descritos apesar do uso de AZT $(14,15,16)$.

Nos 22 casos acompanhados, 15 tiveram exposiçōes percutâneas e, certamente, pelo menos um terço poderiam ser evitados se as medidas de proteção tivessem sido observadas. Um profissional recebeu Zidovudine profilaticamente.

É preciso que os hospitais dêem grande atenção às medidas de prevençāo e se preparem para enfrentar despesas associadas com a transmissão acidental (17)

Tabela 7 - Procedimentos que provocam exposiçāo profissional a sangue ou secreçōes de pacientes HIV positivos no HDT no período de junho de 1986 a outubro de 1992.

\begin{tabular}{llr}
\hline Procedimentos & $\mathrm{N}^{\circ}$ & $\%$ \\
\hline Punção venosa & 06 & 27,4 \\
Manuseio do cateter venoso & 06 & 27,4 \\
Descarte de agulha & 03 & 13,6 \\
Limpeza & 03 & 13,6 \\
Ex. Bioquímico & 01 & 4,5 \\
Necrópsia & 01 & 4,5 \\
Biópsia & 01 & 4,5 \\
Curativo & 01 & 4,5 \\
& & \\
\hline
\end{tabular}

TOTAL
PEREIRA,L.I.A.;SOUZA,M.A.;SOUZA,L.C.S;SILVA,A.B.;GOMES,IIV.;PINTO,R.N.L. Acompanhamento clínico-sorológico de profissionais de saúde expostos a materiais biológicos de pacientes portadores do Virus da Imunodeficiência Humana (HIV). Rev.Pat.Trop.23(1):25-37, jan.jun.1994.

\section{ANEXO}

HOSPITAL DE DOENÇAS TROPICAIS-SUS/GO

COMISSAO DE CONTROLE DE INFECÇĀO HOSPITALAR

FICHA DE NOTIFICAÇĀO A MATERIAIS BIOLÓGICOS

ADAPTADA DO PROTOCOLO PARA PESQUISA DE EXPOSIÇĀO A MATERIAIS

BIOLÓGICOS - ACIDENTE DE TRABALHO. COMISSĀO DE TRABALHOS EM HOSPITAIS ANAMT CEDIDA PELO DR. LUIZ SCHNEIDER

1 - HOSPITAL

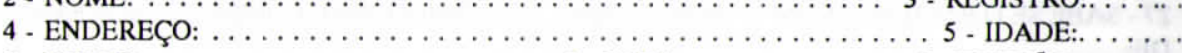

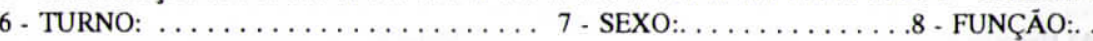

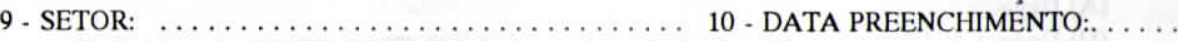

11 - QUANDO ACONTECEU O ACIDENTE DE TRABALHO (AT)?

( )Há menos de 24 horas ( )Há mais de 24 horas - Data do acid.

12 - ESTAVA TRABALHANDO EM REGIME DE PLANTÃO(12 hs)? ()SIM ( )NĀO

13 - O ACIDENTE OCORREU PRÓXIMO À TROCA DE TURNO $( \pm 1$ h)? ( )SIM ( )NĀO

14 - ESTAVA COM PRESSA? ()SIM ( )NĀO

15 - ESTAVA FAZENDO HORA-EXTRA QUANDO OCORREU O AT? ( )SIM ( )NĀO

16 - HA QUANTAS HORAS ESTA(VA) SEM DORMIR? ................................

18 - QUAL O TIPO DE TENSĀO?
() Problemas familiares
() Problemas no trabalho
() Problemas econômicos
() Outros problema

() Não quer responder

19 - TRABALHAVA EM OUTRO LOCAL ()SIM ( )NĀO

TIPO DE ATIVIDADE:

20 - QUANTOS AT SEMELHANTES JÁ TEVE?

() NENHUM () UM () DOIS () TRES () QUATRO OU MAIS

21 - QUAL O TIPO DE MATERIAL BIOLÓGICO ENVOLVIDO NO ACIDENTE
( ) Sangue
( ) Saliva
( ) Escarro
() Liquor
() Urina
( ) Fezes

- OUAL A VIA DE ENTRADA DO MATERIAL BIOLÓGICO NO SEU ORGANISMO?

( ) Através da pele íntegra(perfuraçāo, corte, laceraçāo)

() Através de lesōes da pele já existentes antes do acidente (ferimentos, fissuras etc...)

$\begin{array}{llll}\text { () Mucosa oral () Mucosa ocular () Mucosa respiratória } & \end{array}$

( ) Não houve contato com material biológico 
PEREIRA,L.I.A.;SOUZA,M.A.;SOUZA,L.C.S;SILVA,A.B.;GOMES,I.V.;PINTO,RN.L. Acompanhamento clínico-sorológico de profissionais de saúde expostos a materiais biológicos de pacientes portadores do Vírus da Imunodeficiência Humana (HIV). Rev.Pat.Trop.23(1):25-37, jan./jun.1994.

() Outra via

23 - OCORREU ALG................. 24 - QUAL O TIPO DE LESĀO?
(A) Perfuraçāo
(B) Corte

( )SIM ( )NĀO

25 - OUAL O AGENTE OUE PR........................... (E) Não houve lesåo
(A) Agulha bipoder

(D) Bisturi

$\begin{array}{ll} & \text { (B) Agulha de sutura }\end{array}$

(E) Gillete

(F) Tesoura

(C) Respingos

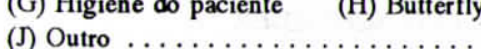

(I) Vidro

(L) Não houve contato com material biológico

26 - O AGENTE QUE PROVOCOU O CONTATO ESTAVA CONTAMINADO COM MATERIAL BIOLOGICO?
(A) SIM
(B) $\mathrm{NĀO}$

$\begin{array}{lll}\text { (C) Nāo, porém permitiu a entrada de material biológico } & \text { (D) nāo sei }\end{array}$

27 - SABE SE O PACIENTE COM CUJO MATERIAL BIOLOGICO TEVE CONTATO É PORTADOR $\mathrm{DE}$
(A) Hepatite tipo B
(B) AIDS
(C) Malária
(D) Doença de Chagas
(E) Outro
(F) Não sei

28 - QUAL A ORIGEM DO PACIENTE?
(A) Ambulatório
(B) Emergência
(C) Hemodiálise
(G) 11
(E) Unidade de internaçăo (F) $\mathrm{N}^{\circ}$ Registro

9 - QUAL O TIPO DE PROCEDIMENTO REALIZADO NO MOMENTO DO AT?

(A) Punçāo venosa de rotina (veia periféria)

$\begin{array}{ll}\text { (C) Punção de veia profunda (Subclávia etc...) } & \text { (D) Punçāo lombar } \\ \text { (E) Injeção intramuscular } & \text { (F) Punçāo pleural }\end{array}$

(E) Injeçăo intramuscula

(G) Curativo infectado

(I) Recolhimento lixo

(H) Punçāo abdominal

(K) Injeção subcutânea

(J) Curativo limpo

(M) Separando roupa na lavanderia

(L) Higiene de paciente

(N) Outro:

30 - QUAL A PARTE DO CORPO ATINGIDA?

$\begin{array}{lllll}\text { (A) Dedo da mão } & \text { (B) Antebraço } & \text { (C) Braço } & \text { (D) Olhos } & \text { (E) Mão }\end{array}$

(G) Abdomen

(H) Tórax

$\begin{array}{lll}\text { (I) Coxa } & \text { (J) } \mathrm{Pe}\end{array}$

(L) Dedos do pé (M) Perna

(N) Outra:
(A) Bloco Cirúrgico
(B) Banco de Sangue
(C) Laboratório
(D) Hemodiálise
(E) Emergência
(F) Ambulatório
(G) Sala de recuperação
(H) Lavanderi
(I) UTI

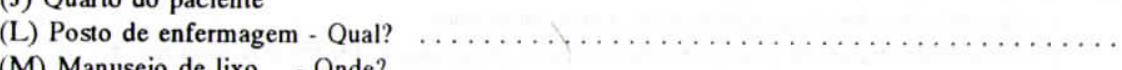

(N) Outro local (Identifique):
PEREIRA,L.I.A.;SOUZA,M.A.;SOUZA,L.C.S;SILVA,A.B.;GOMES,I.V.;PINTO,R.N.L. Acompanhamento clínico-sorológico de profissionais de saúde expostos a materiais biológicos de pacientes portadores do Virus da Imunodeficiência Humana (HIV). Rev.Pat.Trop.23(1):25-37, jan./jun.1994.

32 - EM CASO DE ACIDENTE DE PUNÇÃO POR AGULHA EM QUE FASE DA ATIVIDADE OCORREU O ACIDENTE DE TRABALHO?

(A) Preparaçāo da medicação no posto de enfermagem

(B) No transporte da seringa até o local de aplicação

(C) Antes da aplicação da medicação no paciente

(D) Durante a aplicaçāo da medicação no paciente

(E) Após a aplicação da medicaçāo no paciente

(F) No transporte da seringa até o posto de enfermagem

(G) Após a verificaçăo de glicemia (Haemoglicotest, Dextrostix,...)

(H) No manuseio da caixa para descarte de agulhas

(I) Após coleta de sangue para exames

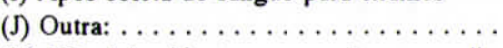

(K) Não foi acidente por punçāo por agulha

33 - TENTOU RECOLOCAR A PROTEÇĀO PLÁSTICA NA AGULHA ( )SIM ( )NĀO

34 - FATORES ASSOCIADOS

Gravidez ()SIM ( )NĀO Diabetes ( )SIM ( )NĀO

$$
\text { Outras: }
$$

35 - FATORES DE RISCO

Prática de risco () Homossexual

$$
\begin{aligned}
& \text { () Heterossexua } \\
& \text { () Bissexual } \\
& \text { () Nenhuma }
\end{aligned}
$$

Viagens nos últimos 30 dias: ()SIM ()NĀO LOCAL

Usa drogas injetáveis:

) SIM ()NÁO

()Individual ()Grupal

( ) SIM ( )NÃO

Antecedentes de DST:

Doença. .... . . Data. ..... Trat.. . . . . .

Tratamento dentário nos últimos 6 meses ()SIM ()NÄO

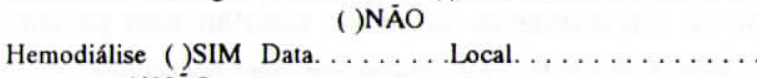

( ) NẤO

Outras situaçöes de risco

36 - TEVE INSTRUCOES DE SEGURANCA NO MANUSEIO DE AGULHAS? ()SIM ()NÄO DESCREVA O ACIDENTE:

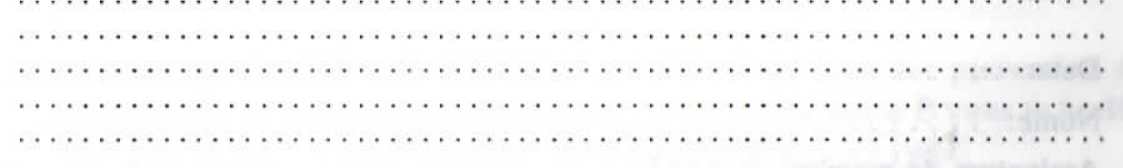


PEREIRA,L.I.A.;SOUZA,M.A.;SOUZA,L.C.S;SILVA,A.B.GOMES,IV.PINTO,RN. A Acompanhamento clínico-sorológico de profissionais de saúde expostos a materiais biológicos de pacientes portadores do Vírus da Imunodeficiência Humana (HIV). Rev.Pat.Trop.23(1):25-37, jan./jun.1994.

37 - Imunização prévia: () Hepatite () Tuberculose

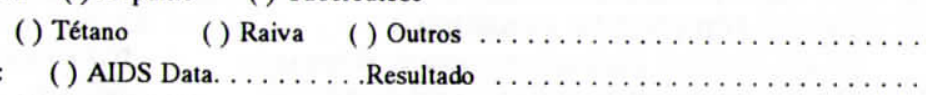

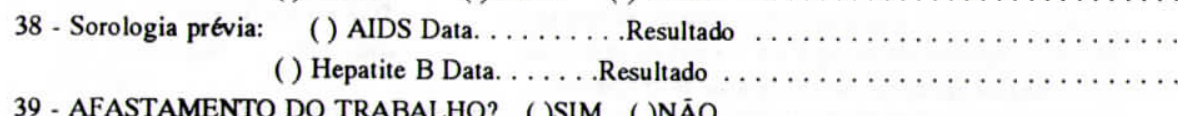
39 - AFASTAMENTO DO TRABALHO? ( )SIM ( )NĀO

SIM. . .Quantos dias?. . . . dias.

40 - EXAME CLÍNICO, DIAGNÓSTICO E CONDUTA

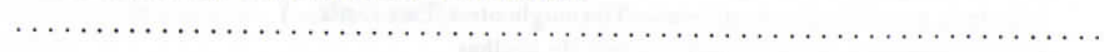

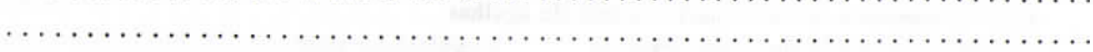

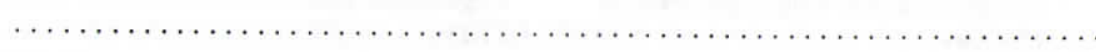

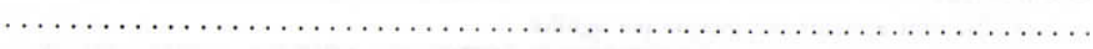
41 - EVOLUÇĀO (Anotar no prontuário de acordo com rotina estabelecida)

\section{HOSPITAL DE DOENÇAS TROPICAIS-SUS/GO COMISSÃO DE CONTROLE DE INFECÇÃO HOSPITALAR TERMO DE CONSENTIMENTO}

O Hospital de Doenças Tropicais - SUS/GO através da Comissão de Infecção Hospitalar está fazendo acompanhamento clínico-laboratorial dos profissionais de saúde que se contaminarem durante o trabalho com pacientes de Síndrome de Imunodeficiência Adquirida, seu sangue ou suas secreçōes.

Concordo em fazer coleta de sangue para Elisa para HIV logo após o acidente, 3 e 6 meses após.

Sei que os resultados serão confidenciais e a minha participação é voluntária.

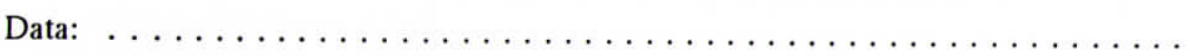

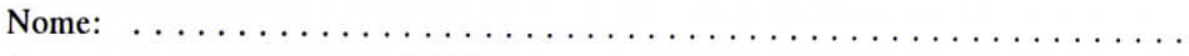

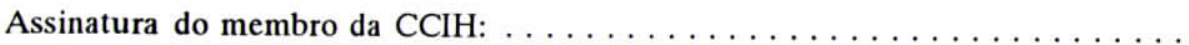

PEREIRA,L.I.A.;SOUZA,M.A.;SOUZA,L.C.S;SILVA,A.B.;GOMES,I.V.;PINTO,R.N.L. Acompanhamento clínico-sorológico de profissionais de saúde expostos a materiais biológicos de pacientes portadores do Vírus da Imunodeficiência Humana (HIV). Rev.Pat.Trop.23(1):25-37, jan.jun.1994.

\section{SUMMARY}

Clinical and serological follow up of health care workers with occupational exposures to biological specimens of AIDS patients

Since 1986, when the first AIDS patient was admitted, the Hospital of Tropical Diseases has been following up health care workers for occupational exposure to AIDS.

From July,1986 to October,1992 five hundred seventy-nine AIDS patients were admitted and 37 occupational exposures were notified; 22 of them due to biological specimens of AIDS patients. Percutaneous exposures were more (12 times) and they resulted from needle - sticks in 17 cases. The fingers were more frequently exposed. Health care workers with these exposures included especially nurses (technicians and auxiliaries). They were tested for HIV antibodies on exposure and 3 and 6 months after. At this time 13 health care workers have been tested at least 180 days after exposure, 3 have had only the first test and the others haven't completed the follow up yet.

Seroconversions have not been identified. And none of the health care workers have shown clinical symptons consistent with acute HIV infection.

Keywords: Hospitalar infection, Occupational exposures

\section{REFERÊNCIAS BIBLIOGRÁFICAS}

01. BRENNAN,T.A. Transmission of the human immunodeficiency virus in the health care setting-time for action. M.Engl.J.Med.,324(21):1504-1508,1991.

02. CENTERS FOR DISEASE CONTROL (CDC). Guidelines for prevention of transmission of human immunodeficiency virus and hepatitis $B$ virus to health care and public - Safety workers MMWR,138(5-6):1-37,1989. 
03. HENDERSON,D.K. \& GERBERDIN,J.L. Prophylactic Zidovudine after occupational exposure to the human immunodeficiency virus. An interm analysis. J.Inf.Dis.,160(2):321-6,1989.

04. HENDERSON,D.K.;FAHEY,B.J.;WILLY,M. et al. Risk for occupational transmission of Human Immunodeficiency Virus type 1 associated with clinical exposure: a prospective evolution. Ann.Inters.Med.,113:740,1990.

05. JEFFRIES,D.J. Zidovudine after occupational exposure to HIV. BMJ.,302:134950,1991 .

06. KLEIN,R.S.;PHELAN,J.A.;FREEMAN,K.;SCHABLE,C.; FRIEDLAND,G.H. et al. Low occupational risk of human immunodeficiency virus infection among dental professonals. Engl.J.Med.,318:86-90,1988.

07. KUHLS,T.L. \& CHERRY,J.D. The management of health care workers' accidental parenteral exposures to biological specimens of HIV soropositive individuals. Infection Control,8(5):211-213,1987.

08. KUHLS,T.L.;VIKER,S.;PARRIS,N.B.;GARAKIAM,A.; SULLIVAN BDYAI,J.;CHERRY,J.D. Occupational risk of HIV, HBV and HSVZ infections in health care personnel caring for AIDS patients. Am.J.Public Health,77:1306-9,1987.

09. LANGE,J.M.A;BOUCHER,C.A.B.;HOLLAR,C.E.M. et al. Failure of Zidovudine prophylaxis after accidental exposure to HIV-1. N.Engl.J.Med.,322(19):13757,1990 .

10. MACHADO,A.A.;COSTA,J.C.;GIR,E.;MORIYA,T.M.; FIQUEIREDO,J.F.C.Risco de infecção pelo vírus da imunodeficiência humana (HIV) em profissionais de saúde.Rev.Saúde Publ.S.Paulo,26(1):54-6,1992.

11. MARCUS,R. \& BELL,D.M. Occupational risk of HIV infection in health care

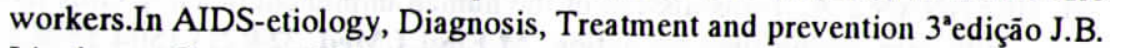
Lippincott Company.Philadelphia,1992.

12. MARCUS,R. \& CDC COOPERATIVE NEEDLESTICK GROUP. Surveillance of health care workers exposed to blood from patients infected with Human Immunodeficiency Virus. N.Engl.J.Med 3/9:1118-23,1988.
PEREIRA,LJIA-SOUZA,M.A.SOUZA,L.C.S;SILVA,A.B.GOMES,IV.PINTO,R.N.L Acompanhamento clínico-sorológico de profissionais de saúde expostos a materiais biológicos de pacientes portadores do Virus da Imunodeficiência Humana (HIV). Rev.Pat.Trop.23(1):25-37, jan./jun.1994.

13. MARCUS,R.;TOKARS,J.L.;CULVER,D.H et al. for Cooperative Needlestick Surveillance Group. Zidovudine use after occupational exposure to HIV infected blood (asbtr.979). In programs and abstracts of the Interscience conference in antimicrobial agents and chemotherapy, Chicago,September 29 - October 2,1991.

14. Protocolo para pesquisa de exposição a materiais biológicos - acidentes de trabalhos em hospitais. ANAMT. Material cedido pelo Dr. Luiz O.Schneider.

15. PULIESE,R.N. \& LAMPINEU,T. Prevention of human immunodeficiency virus infection: our responsabilities as health care professionals. Am.J.Infec. Control,17:1-22,1989

16. RAMOS,M.C. \& FERREIRA,J. SIDA - normatização para acidentes de trabalho. R.AMRIGS,33(2):174-175,1989.

17. SOARES,O. \& PEIXOTO,J.C. Graus de risco de que estão expostos os trabalhadores em intituiçōes hospitalares. Rev.Bras de Enf.Brasília,40(2/3),1987.

18. ZUGER,A. \& MILLES,S.H. Physicians, AIDS, and occupational risk. Historic traditions and ehtical obligations. JAMA,258:1924-1928,1987. 